\title{
Pseudodiploexochus tabularis (Barnard), novo registro de Armadillidae (Crustacea, Isopoda, Oniscidea) para o Brasil ${ }^{1}$
}

\author{
Elis R.C. Lopes ${ }^{2}$ \\ Paula Beatriz Araujo 2 \\ Georgina Bond-Buckup ${ }^{2}$
}

\begin{abstract}
Pseudodiploexochus tabularis (Barnard, 1932), new record of Armadillidae (Isopoda, Oniscidea) from Brazil. Specimens of terrestrial isopods collected in Rio Grande do Sul were identified as Pseudodiploexochus tabularis (Barnard, 1932). This is the first record of the species from Brazil.

KEY WORDS. Isopoda, Oniscidea, Armadillidae, Pseudodiploexochus tabularis, new record, Brazil
\end{abstract}

A família Armadillidae está representada no Brasil pelos gêneros Cubaris Brandt, 1833, Diploexochus Brandt, 1833, Pseudodiploexochus Arcangeli, 1934 e Venezillo Verhoeff, 1928 (SOUZA-KURY 1998).

O gênero Pseudodiploexochus, embora muitas vezes confundido com o gênero Reductoniscus Kesselyak, 1930, é um gênero válido e as diferenças entre os dois foram estabelecidas por FERRARA \& TAITI $(1983,1990)$. A maioria das espécies de Pseudodiploexochus tem distribuição no continente africano (FERRARA \& TAITI 1978; TAITI \& Ferrara 1979, 1984). As espécies $P$. insularis (Vandel, 1977), $P$. leleupi (Vandel, 1977) e P. mellissi (Vandel, 1977) são registradas para a Ilha de Santa Helena, enquanto que $P$. tabularis (Barnard, 1932) tem registro na Ilha Ascenção (LEISTIKOW \& WÄGELE 1999). No Brasil há somente o registro de $P$. gibbus (Lemos de Castro, 1972), para o Estado de São Paulo (LEMOS DE CASTRO 1972).

Durante o inventariamento da fauna de isópodos terrestres do Estado do Rio Grande do Sul, foram encontrados exemplares de P. tabularis, constituindo o primeiro registro da espécie para o Brasil.

O material examinado encontra-se depositado no Setor de Crustáceos Superiores do Departamento de Zoologia (UFRGS).

\section{Pseudodiploexochus tabularis (Barnard, 1932)}

Segundo TAITI \& FERRARA (1979) a espécie caracteriza-se por possuir olhos pequenos, com dois ou três omatídios, estrutura basal constituída de proeminências circulares, entre as quais estão dispostas as setas escamosas, céfalo rugoso, sem

1) Contribuição número 365 do Departamento de Zoologia, Universidade Federal do Rio Grande do Sul.

2) Programa de Pós-Graduação em Biologia Animal, Departamento de Zoologia, Instituto de Biociências, Universidade Federal do Rio Grande do Sul. Avenida Bento Gonçalves 9500, prédio 43435, sala 213, 91501-970 Porto Alegre, Rio Grande do Sul, Brasil. 
tubérculo, primeiro pereionito com duas globosidades grandes na parte anterior, primeiro ao quarto pereionito com tubérculos pouco evidentes, estando aparentes a partir do sexto. Além disso, apresenta o primeiro pereionito com o lobo interno do "schisma" arredondado, muito saliente com relação ao lobo externo e o segundo, com lobo interno muito saliente e o externo triangular. $\mathrm{O}$ telso apresenta ápice truncado e ângulos largamente arredondados.

Material examinado. BRAsIL, Rio Grande do Sul: Dom Pedro de Alcântara, 21.VI.1991, 15 fêmeas, 3 machos, em serapilheira de Mata Atlântica (UFRGS 2885); Dom Pedro de Alcântara, 21.XI.1996, 7 fềmeas, 1 macho, em serapilheira de Mata Atlântica (UFRGS 2884); Osório, Morro Borússia, 09.III.1991, 1 macho, em serapilheira de Mata Atlântica (UFRGS 2886); Capão da Canoa, Arroio Teixeira, 10.IX.1998, 2 fêmeas, em serapilheira e troncos podres de mata paludosa de Restinga (UFRGS 2489); Capão da Canoa, Arroio Teixeira, 25.IX.1999, 2 fêmeas, em serapilheira de mata paludosa de Restinga (UFGRS 2513).

Distribuição. A espécie tem registros de ocorrência na África do Sul (TAITI \& Ferrara 1979) e na Ilha Ascenção (Ferrara \& TAiti 1981). No Brasil, P. tabularis foi registrada na região nordeste do Rio Grande do Sul, na faixa costeira do Estado.

\section{REFERÊNCIAS BIBLIOGRÁFICAS}

Ferrara, F. \& S. Taiti. 1978. Pseudodiploexochus madagascariensis, new species of Armadillidae (terrestrial Isopoda) from Madagascar. Monitore zool. ital. 4: 81-83.

— 1981. Terrestrial Isopods from Ascension Island. Monitore zool. ital. 14: 189-198. 1983. Contributions à l'étude de la faune terrestre des îles granitiques de l'archipel des

Séchelles. Isopodi terrestri. Annls Mus. r. Afr. centr., (Sci. Zool.) Ser. 8, 240: 1-92.

1990. Two new species of Reductoniscus Kesselyak, 1930 from New Guinea (Crustacea,

Oniscidea, Armadillidae). Revue suisse Zool. 97: 489-497.

LEISTIKOW, A. \& J.W. WÄGELE. 1999. Checklist of the terrestrial isopods of the new world (Crustacea,

Isopoda, Oniscidea). Revta bras. Zool. 16 (1): 1-72.

LEMOS DE CASTRO, A. 1972. Considerações sobre o gênero Reductoniscus, com descrição de uma espécie nova. Rev. Brasil. Biol. 32 (3): 347-349.

SouZA-KURY, L.A. 1998. Malacostraca-Peracarida. Isopoda. Oniscidea, p. 653-674. In: P.S. YounG

(Ed.). Catalogue of Crustacea of Brazil. Rio de Janeiro, Museu Nacional, 503p.

TAITI, S. \& F. FERrARA. 1979. Il genere Pseudodiploexochus Arcangeli, 1934 (Armadillidae, Oniscoidea, Isopoda). Revue Zool. afr. 93 (1): 151-184.

. 1984. Isopodi terrestri delle Isole Comore (Crustacea, Oniscoidea). Revue Zool. afr. 98 (1): 141-164.

Recebido em 24.VIII.2000; aceito em 08.VI.2001. 